\section{Tibiaplateau-Frakturen lassen sich auch mit Fremdknochen gut reparieren}

Frakturen des Tibiaplateaus werden traditionell offen reponiert und mit Autotransplantaten aus dem Darmbein repariert. Allotransplantate bieten demgegenüber zwar manche Vorteile, erfordern indes einigen Aufwand. Doch der kann sich lohnen, wie eine chinesische Studie zeigt.

Ü ber ihre Erfahrungen mit gefrorenen Frischknochen-Allotransplantaten haben Orthopäden der Jilin-Universität in Changchun berichtet. Sie hatten 22 Patienten im Durchschnittsalter von 35 Jahren mit der Methode behandelt. Alle Operierten wurden über einen Zeitraum von ein bis zwei Jahren (im Mittel 16,5 Monate) nachbeobachtet. Der klinische Erfolg wurde mithilfe des für Tibiakopf-Frakturen entwickelten Rasmussen-Scores sowie röntgenologisch ermittelt.

Operationstechnisch stießen die chinesischen Spezialisten von anterolateral zum Knie vor. 1,5-2 cm unterhalb des Tibiaplateaus wurde ein Hohlraum geschaffen, die Fraktur reponiert und die Höhle mit Fremdknochen gefüllt. Die Fraktur wurde mit einer L-Platte fixiert.

Im postoperativen Follow-up zeigte sich bei zwölf der 22 Patienten gemäß dem Rasmussen-Score ein exzellentes, bei sechs weiteren ein gutes Ergebnis. Ausreichend war das Resultat in drei und schlecht in einem Fall. Radiologisch waren bei zwei Allotransplantaten Resorptionszeichen ohne Nachweis einer Verbindung mit dem Wirtsgewebe zu erkennen. Damit erreichte die Quote erfolgreich eingewachsener Transplantate knapp $91 \%$.

Nicht unbeträchtlich war allerdings der Aufwand, der mit dem Fremdknochen betrieben werden musste, um die Empfänger vor Infektionen, etwa mit Hepatitis- oder HI-Viren zu schützen. Die $2 \times 1 \times 1 \mathrm{~cm}$ großen Fragmente wurden den auf Infekte gescreenten Spendern binnen $24 \mathrm{~h}$ post mortem aus den Femurkondylen entnommen. Weichteilgewebe musste unter sterilen Kautelen im Operationssaal entfernt werden. Blut und Knochenmark spülte man unter Hochdruck mit Salzlösung aus.

Die Knochenblöcke - auf einer Seite aus Kortikalis, sonst aus Spongiosa be- stehend - wurden für vier Wochen bei $-70^{\circ} \mathrm{C}$ tiefgefroren und anschließend mit einer Dosis von $25 \mathrm{kGy}$ mit Kobalt 60 bestrahlt. Vor der Übertragung wurden die Transplantate 30 Minuten in Polyvidon-Jod getaucht, um Bakterien abzutöten. Anschließend folgte eine weitere Spülung mit Salzlösung. Schließlich weichte man die Knochenstücke $15 \mathrm{Mi}$ nuten in 75\%-igen Alkohol ein, bevor abschließend mit Gentamicin nachgespült wurde.

Fazit: Die übliche Verwendung von Autotransplantaten aus dem Darmbein zum Aufbau von Plateaufrakturen der Tibia hat neben immunologischen und infektiologischen Vorteilen auch einige Nachteile: 10-25\% der Patienten entwickeln Komplikationen bis hin zur Fraktur des Os ilium. Fremdtransplantate können helfen, diese Risiken zu umgehen, wie die vorliegende chinesische Studie demonstriert. Die Erfolgsquote ist beachtlich - der dafür nötige technische Aufwand freilich auch. Dr. Robert Bublak

Feng $W$ et al. The use of deep frozen and irradiated bone allografts in the reconstruction of tibial plateau fractures. Cell Tissue Bank 2012; doi: 10.1007/s10561-012-9342-0

Kommentar: In ihrer Studie berichteten Feng et al. bei Tibiakopf-Impressionsfrakturen durch die Verwendung von Fremdknochentransplantaten zur Rekonstruktion über ein gutes knöchernes Einheilen. Die Ergebnisse zeigen, dass Fremdknochen eine attraktive Alternative zur Entnahme von Eigenknochen darstellt, da es hier zu Schmerzen an der Entnahmestelle oder Wundheilungsstörungen kommen kann. Allerdings dürfte das relativ junge Durchschnittsalter von 35 Jahren der chinesischen Patienten die ossäre Integration des Fremdknochens begünstigt haben. Hierzulande ist das Durchschnittsalter bei einer Tibiakopffraktur wesentlich höher und Eigen-

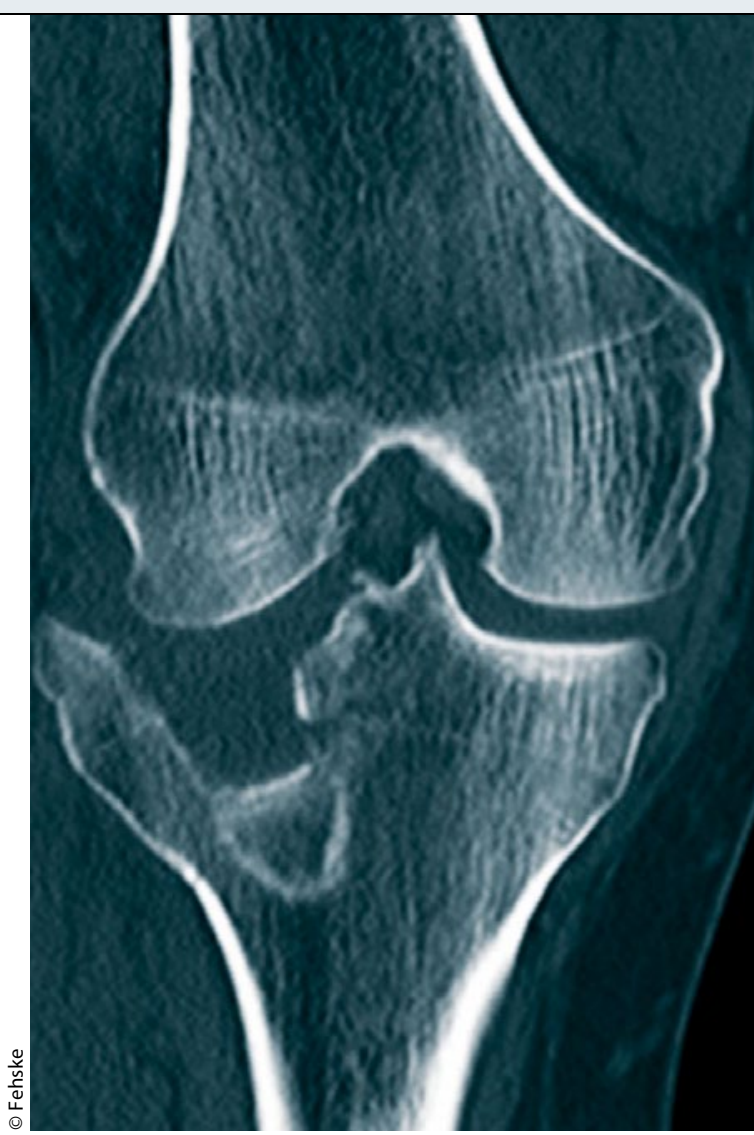

Laterale Impressionsfraktur der Tibia

knochentransplantaten können dann durchaus Vorteile bei der ossären Integration bieten. Da auch das Risiko von AbstoBungsreaktionen und Infektionen geringer ist, sollte die Eigenknochentransplantation daher weiterhin als eine Behandlungsoption berücksichtigt werden.

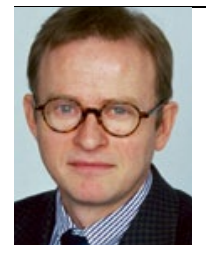

Prof. Volkmar Jansson Orthopädische Klinik und Poliklinik der LMU Klinikum Großhadern Marchioninistr. 15 81377 München 